\title{
Parotid sialolithiasis and sialadenitis in a 3- year-old child: a case report and review of the literature
}

\author{
Nur Eliana Ahmad Tarmizi', Suhana Abdul Rahim², Avatar Singh Mohan Singh², Lina Ling Chooi², \\ Ong Fei Ming ${ }^{2}$ and Lum Sai Guan ${ }^{*^{*}}$ (D)
}

\begin{abstract}
Background: Salivary gland calculi are common in adults but rare in the paediatric population. It accounts for only $3 \%$ of all cases of sialolithiasis. Parotid ductal calculus is rare as compared to submandibular ductal calculus.

Case presentation: A 3-year-old boy presented with acute painful right parotid swelling with pus discharge from the Stensen duct. Computed tomography revealed calculus obstructing the parotid duct causing proximal ductal dilatation and parotid gland and masseter muscle oedema. The child was treated with conservative measures, and subsequently the swelling and calculus resolved.

Conclusions: Small parotid duct calculus in children may be successfully treated with conservative measures which obviate the need for surgery. We discuss the management of parotid sialolithiasis in children and conduct literature search on the similar topic.
\end{abstract}

Keywords: Sialolithiasis, Sialadenitis, Salivary calculi, Parotid gland, Salivary ducts, Paediatrics

\section{Background}

Sialolithiasis is an obstructive disorder of salivary ductal system caused by formation of stones within the salivary gland or its excretory duct [1]. The resulting salivary flow obstruction leads to salivary ectasia, gland dilatation and ascending infection [2]. Sialolithiasis is common in adults but rarely seen in the paediatric population, which accounts for only $3 \%$ of cases. Majority (80 to $90 \%$ ) of sialolithiasis occur in the submandibular gland; only 10 to $20 \%$ involve the parotid gland. It usually affects the salivary duct more than the gland [2]. Due to the small size of parotid duct calculi and its radiolucency on conventional radiograph, it is frequently missed [3]. We report a child who was diagnosed with right parotid calculus mimicking right parotid abscess after

\footnotetext{
* Correspondence: lumsg@ukm.edu.my

'Department of Otorhinolaryngology - Head and Neck Surgery, Hospital Canselor Tuanku Muhriz, Universiti Kebangsaan Malaysia Medical Centre, Jalan Yaakob Latiff, Bandar Tun Razak, 56000 Cheras, Kuala Lumpur, Malaysia Full list of author information is available at the end of the article
}

performing computed tomography $(\mathrm{CT})$ of the neck. The unusual presentation, CT findings and its subsequent management were discussed.

\section{Case presentation}

A 3-year-old Malay boy presented with 5 days history of painful right cheek swelling, which was gradually increasing in size. It was followed by fever, cough and runny nose for 1 day. The swelling was not related with eating and his oral intake was not affected. This was the first episode of such swelling. There was no history ear discharge, trauma or toothache prior to the swelling. Examination revealed a firm swelling at the right parotid region extending to the right cheek, measuring $3 \times 3 \mathrm{~cm}$. It was tender and warm on touch; the overlying skin was not inflamed (Fig. 1). There was no trismus and hydration was good. Oral cavity examination noted pus discharge from the right Stensen duct opening (Fig. 2). The surrounding buccal mucosa was not inflamed and not swollen. There were no carious teeth, and 
a

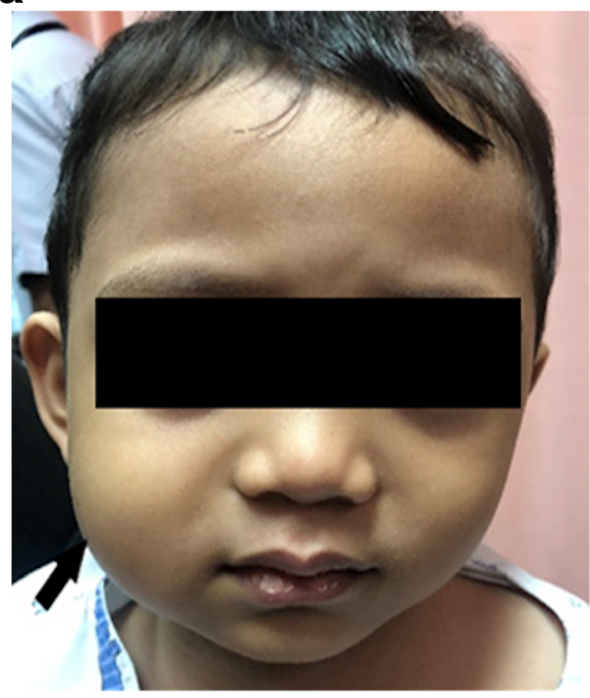

b

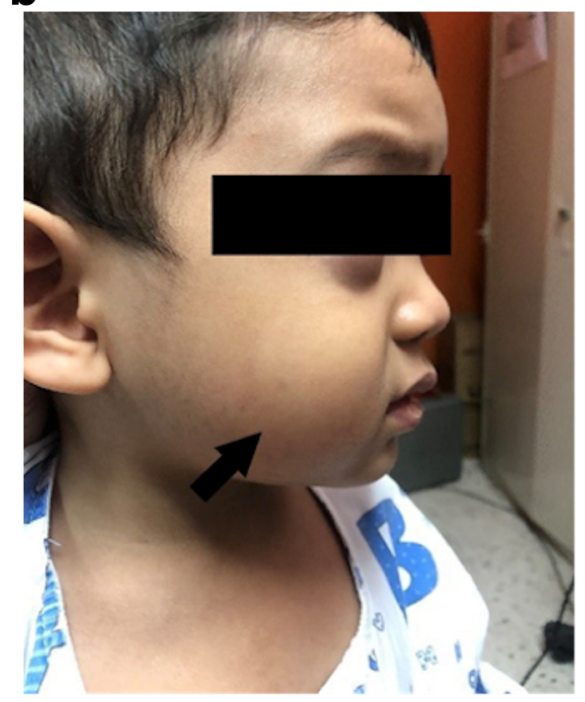

Fig. 1 a, b Right parotid swelling extending to the cheek area (arrow)

examination of oropharynx was normal. Both Wharton ducts were patent with free salivary flow. No solid mass was felt at the buccal region near the parotid duct opening by bimanual palpation. He was admitted to the hospital, and intravenous antibiotic was initiated. CT scan of the neck performed showed diffuse homogenous swelling of the right parotid gland and right masseter muscle. The Stensen duct was dilated measuring $6 \mathrm{~mm}$ in diameter (Fig. 3a), and the wall was thickened. There was a tubular-shaped hyperdense lesion measuring 10 $\mathrm{mm}$ in length within the distal part of parotid duct, consistent with a parotid ductal calculus (Fig. 3b). There

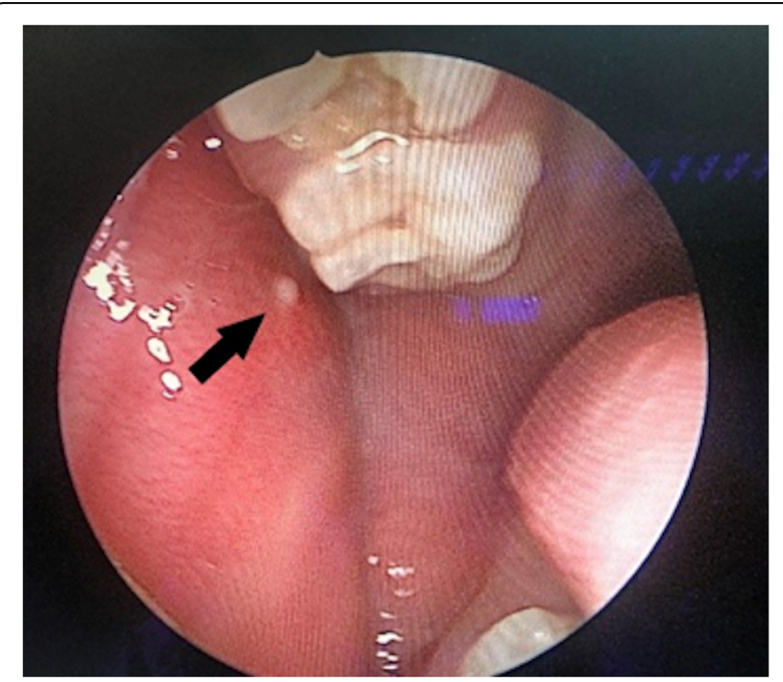

Fig. 2 Intraoral examination noted pus discharge from the right Stensen duct opening (arrow) was no stricture of the duct noted, and no other calculi or abscess collection was seen in the enlarged parotid gland.

He was treated as acute sialadenitis and sialectasis secondary to parotid duct sialolithiasis. The masseter muscle enlargement was due to oedema caused by inflammation surrounding the enlarged parotid duct. Full blood count revealed mild leukocytosis with neutrophils predominant. The calcium level was within normal range. The renal and liver function tests were normal. The pus culture from the Stensen duct revealed mixed growth of more than three types of organisms, including group A Streptococcus, Staphylococcus aureus, Staphylococcus epidermidis and Haemophilus species, most likely due to contamination and thus misleading. The sensitivities were not performed and not reported by microbiologist.

Incision and removal of the parotid duct calculus via intraoral approach was planned under general anaesthesia, but the parents declined. The patient was treated conservatively with intravenous antibiotic amoxicillin and clavulanate (Augmentin) for 5 days duration and syrup paracetamol as analgesia. The pus was drained manually by external compression and milking from the Stensen duct opening daily. He was encouraged to take sialagogue such as orange candy to stimulate salivary flow and drink plenty of fluids to ensure good hydration. The parotid and masseter swelling gradually reduced, and the pus discharge from Stensen duct resolved on conservative medical therapy. He was afebrile since admission, and the pain subsided. The child or the parents did not notice any stone removed from the oral cavity or swallowed. He 

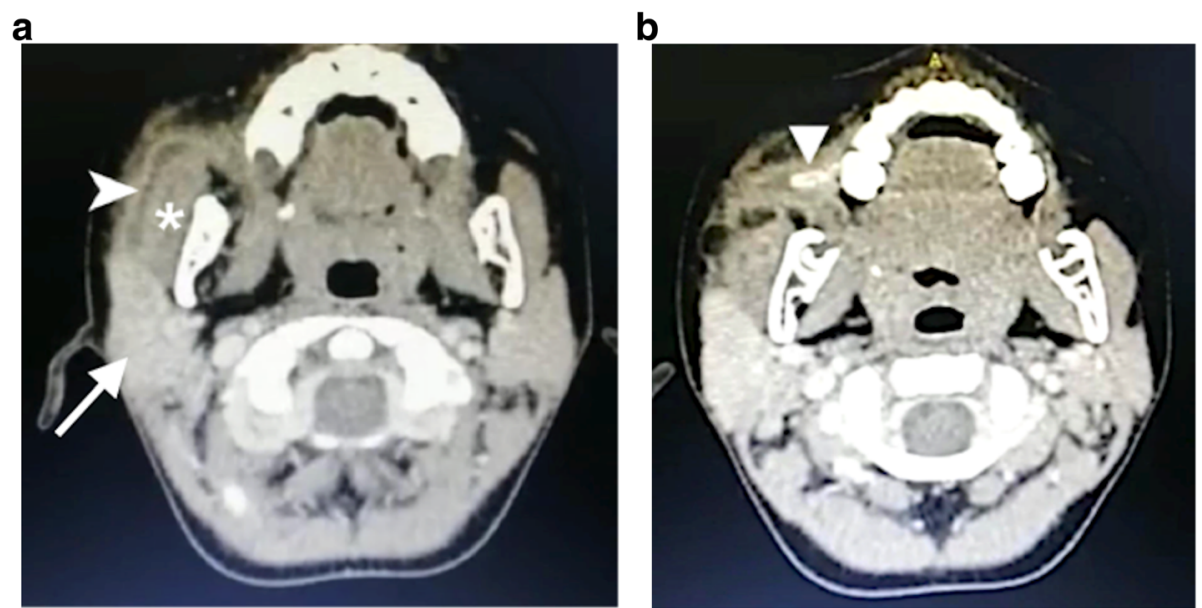

Fig. 3 a Axial CT shows dilated Stensen duct with thickened wall (arrow head) overlying the swollen masseter muscle (asterisk) and enlarged parotid gland (arrow). b A hyperdense tubular-shaped stone is seen in the distal part of the dilated parotid duct (arrow head)

was subsequently discharged with continuation of oral antibiotic.

Upon 1 month review in the outpatient clinic, the parotid swelling had totally subsided. There was no pus discharge noted from the Stensen duct opening. Sialendoscopy was offered for both diagnostic and therapeutic purposes but the parents refused, as the patient was asymptomatic then. An ultrasonography of the parotid gland was performed and revealed normal gland tissue with no calculus seen (Fig. 4). The parents opted for watchful waiting, and there was no sign or symptom of recurrence at 6 months follow-up.

\section{Discussion}

Sialolithiasis is an uncommon finding in parotid glands and rarely seen in paediatric patients [2]. Several manuscripts regarding parotid gland sialolithiasis in children were obtained during literature search, but mainly limited to case report (Table 1). This is the youngest patient with parotid sialolithiasis that we have ever encountered in our centre.

Thorough history and examinations as well as appropriate diagnostic imaging are essential to avoid misdiagnosis. The presentation of parotid sialolithiasis varies in different phases. During acute infection, patient may present with pain, swelling, redness and discharge from the duct, which can be precipitated by meals. However, in the chronic phase, the patient may present with recurrent painful swelling or non-resolving infections of the gland which usually reduce in size [8]. In this case, the boy presented with acute parotid and cheek swelling mimicking parotid abscess. There was no history of recurrent parotid swelling to suggest salivary ductal calculi. The CT scan performed subsequently revealed the underlying pathology: a calculus impacted at the distal part of the parotid duct. In our opinion, this stone caused total obstruction to the salivary outflow resulting in salivary stasis and the dilatation of the parotic duct.

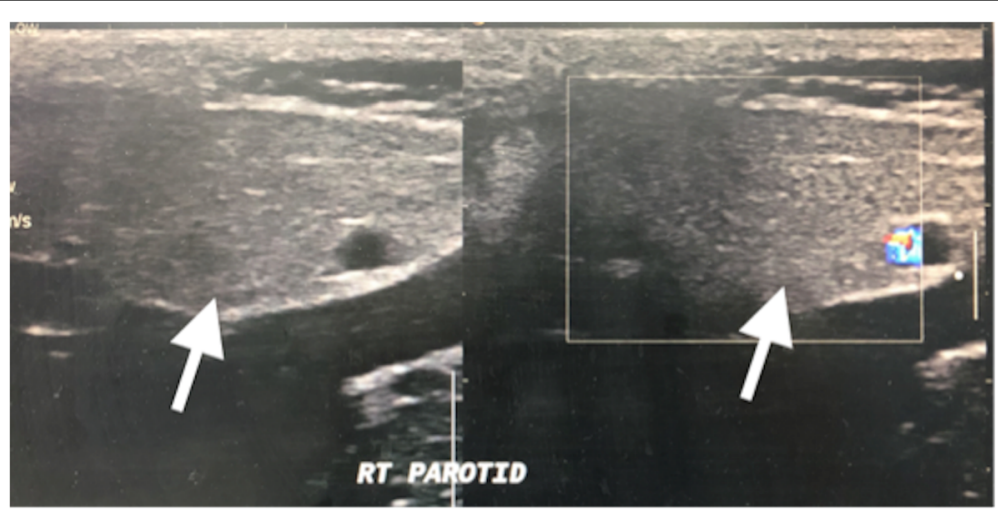

Fig. 4 Ultrasonography shows normal right parotid gland with homogenous echogenicity. The parotid duct was not dilated and no residual calculus are seen 
Table 1 Summary of published case reports on paediatric parotid sialolithiasis, the characteristics, presenting symptoms, diagnostic imaging and treatment

\begin{tabular}{lllllll}
\hline Author (year) & Age & Gender & Location & Symptoms & Diagnostic imaging & Treatment \\
\hline Kim et al. [1] & 2 & M & Duct & Pain, pus, swelling & CT & Intraoral incision \\
Bodner [3] & 5 & F & Duct & Pain, swelling & CT & Intraoral incision \\
Laskawi et al. (2006) [4] & 4 & M & Duct & Pain, swelling & CT & Intraoral incision \\
Horie et al. (1995) [5] & 4 & F & Duct & Pus, swelling & Conventional radiography & Intraoral incision \\
Kaufman [6] & 4 & F & Duct & Small mass, pus, swelling & Conventional radiography & Intraoral sialolithomy \\
McCullom et al. [7] & 8 & F & Duct & Pain, swelling & Conventional radiography & Conservative \\
\hline
\end{tabular}

As a consequence, secondary bacterial infection set in and caused ascending infection to the parotid gland. The dilatation of the parotid duct and the masseter muscle oedema explained the cheek swelling clinically. However, we could not explain how the stone was formed in the parotid duct in this child.

There is no established pathogenesis of sialolithiasis, but it is assumed to be formed by deposition of organic and inorganic materials. The central core is formed by precipitation of calcium salts bound by organic substances which consist of altered salivary mucins, bacteria and desquamated epithelial cells [1]. Various aetiologies of parotid duct calculus formation have been proposed. Foods, bacteria or foreign body may ascend the duct creating a nidus for calcification, which is combined with inflammatory cells to form parotid calculi. This is different compared to submandibular duct calculi as the nidus is formed by mucus [9]. Other factors that have been suggested were alkalinisation of saliva, physical trauma, stagnation of saliva, gout and nephrolithiasis. Ultrasound kidney was done in our patient and the result was normal. The most likely aetiologic factor in this case was bacterial infection as evidenced by the elevated white cells count and predominantly neutrophils. However, the bacterial infection could also be secondary to salivary stasis due to obstruction by ductal calculi. Active infection would further activate inflammatory response and subsequently cause increase in salivary $\mathrm{pH}$, supersaturation of saliva, reduced salivary flow rate and increased incidence of stone formation [1].

Various modalities of investigation are available to assist in the diagnosis of a parotid stones. About $60 \%$ of stones in the parotid gland are radio-opaque in conventional radiography, as compared to $80-90 \%$ of stones in the submandibular gland [10]. In contrast, up to $90 \%$ of salivary duct stones can be detected with ultrasonography. It appears as hyperechoic mass with posterior acoustic shadow. Stones that are radiolucent on conventional radiograph can be seen with ultrasound [11]. However, a small stone less than $1.5 \mathrm{~mm}$ may not be evident on ultrasonography. CT scans are more sensitive in comparison to X-ray and ultrasound in detecting sialolithiasis. It is also good in detecting abscess and to delineate the ductal anatomy. Specificity of CT scan alone in diagnosing focal parotid inflammatory disease is only $75 \%$, but increased to $90 \%$ when combined with clinical information and findings [12]. Other modalities that are useful include sialography and MRI. In this case, CT scan was done and able to detect the stone in the distal parotid duct that was measured approximately 10 $\mathrm{mm}$ in length. There was no repeat CT scan done subsequently. The ultrasonography performed may have missed the small residual calculus.

Treatment modalities of parotid duct calculi can be either conservative or surgical therapy, depending on the size and the location of the stone. Small and distally located stone can be treated conservatively awaiting spontaneous expulsion [10]. Conservative treatment includes maintaining patient's good hydration, external hot compress, sialagogues and antibiotic if inflammation or infection is evident [12]. Cornell et al. reported a case of an 8-year-old child that was treated conservatively with antibiotic, advised on hydration, hot pressure and lemon drops to promote salivary flow. The calculus was expelled subsequently [7]. However, if conservative management fails, surgery has to be considered. Surgical approach is determined by the size of the stone and the location of the stone in the duct. Extracorporeal short wavelength lithotripsy, sialendoscope alone or combined with transoral surgical approach give 95\% clinical resolution. A modern diagnostic and therapeutic approach was successful in most cases and avoids invasive sialectomy [13]. The patient in this case responded well to medical treatment. Should the problem recur, sialendoscopy would be a good option for diagnostic and therapeutic purpose. The fate of the calculus in this case is unknown, limited by the parental refusal of endoscopic and surgical interventions. Most possibly, it has been expelled spontaneously or resolved following medical therapy. This, however, may suggest that a small parotid duct calculus in children can be successfully treated with conservative measures which obviate the need for surgery.

\section{Conclusion}

Parotid duct calculus in a paediatric patient is extremely rare but should always be considered as one of the 
differential diagnoses when the patient present with a painful parotid swelling. Besides, the diagnosis cannot be ruled out even if there is no history of recurrent parotid swelling. A combination of good history, thorough examinations and detailed investigations are of paramount importance in managing this condition. In this particular case, it was successfully treated by conservative therapy.

\section{Abbreviations}

CT: Computed tomography; MRI: Magnetic resonance imaging

\section{Acknowledgements}

Not applicable

\section{Authors' contributions}

$\mathrm{NE}$ and SR contributed to the conception and design of the work. Analysis and interpretation of data were performed by FM, LL, AS and SG. NE, SR, FM, $L L$ were involved in drafting of the work, and it was revised by NE, AS and

SG. All authors read and approved the final manuscript.

\section{Funding}

None declared.

\section{Availability of data and materials}

No

Ethics approval and consent to participate

The need for ethics approval was waived by the institutional ethics committee.

\section{Consent for publication}

Written informed consent for publication was obtained from the parent of the patient.

\section{Competing interests}

The authors declare that they have no competing interests.

\section{Author details}

${ }^{1}$ Department of Otorhinolaryngology - Head and Neck Surgery, Hospital Canselor Tuanku Muhriz, Universiti Kebangsaan Malaysia Medical Centre, Jalan Yaakob Latiff, Bandar Tun Razak, 56000 Cheras, Kuala Lumpur, Malaysia. 2Department of Otorhinolaryngology- Head and Neck Surgery, Hospital Taiping, 34000 Taiping, Perak, Malaysia.

Received: 26 May 2020 Accepted: 18 August 2020

Published online: 14 September 2020

References

1. Kim DH, Song WS, Kim YJ, Kim WD (2013) Parotid sialolithiasis in a two-yearold boy. Korean J Pediatr 56(10):451-455. https://doi.org/10.3345/kjp.2013. 56.10 .451

2. Lustmann J, Regev E, Melamed Y. Sialolithiasis (1990). A survey on 245 patients and a review of the literature. Int J Oral Maxillofac Surg 19(3):135138. doi:https://doi.org/10.1016/s0901-5027(05)80127-4

3. Bodner L (1999) Parotid sialolithiasis. J Laryngol Otol 113(3):266-267. https:// doi.org/10.1017/s0022215100143750

4. Laskawi R, Schaffranietz F, Arglebe C, Ellies M (2006) Inflammatory diseases of the salivary glands in infants and adolescents. Int J Pediatr Otorhinolaryngol 70(1):129-136. https://doi.org/10.1016/j.jporl.2005.06.012

5. Horie N, Shimoyama T, Tanebayashi Y, Ide F (1995) Parotid sialolithiasis in a child. J Clin Pediatr Dent 20(1):61-62

6. Kaufman S (1968) Parotid sialolithiasis in a child. Am J Dis Child 115(5):623624. https://doi.org/10.1001/archpedi.1968.02100010625017

7. McCullom C, Lee CYS, David IB (1991) Sialolithiasis in an 8-year-old child: case report. Pediatr Dent 13.231-233

8. Hathiramani V, Krishnan J, Redkar RG (2017) Parotid duct calculi: a report of two cases. J Pediatr Neonatal Care 7(4):00293. https://doi.org/10.15406/jpnc. 2017.07.00293
9. Pollack CV Jr, Severance HW Jr (1990) Sialolithiasis: case studies and review. J Emerg Med 8(5):561-565. https://doi.org/10.1016/0736-4679(90)90450-a

10. Rzymska-Grala I, Stopa Z, Grala B, Gołębiowski M, Wanyura H, Zuchowska A et al (2010) Salivary gland calculi - contemporary methods of imaging. Pol 」 Radiol 75(3):25-37

11. Jäger L, Menauer F, Holzknecht N, Scholz V, Grevers G, Reiser M (2000) Sialolithiasis: MR sialography of the submandibular duct--an alternative to conventional sialography and US? Radiology 216(3):665-671. https://doi.org/ 10.1148/radiology.216.3.ro0se12665

12. Oka T, Nomura J, Matsumura $Y$ et al (2006) A case of sialolithiasis in a child. J Clin Pediatr Dent 31(2):139-141. https://doi.org/10.17796/jcpd.31.2. k8461578232g26tr

13. Capaccio P, Canzi P, Gaffuri M, Occhini A, Benazzo M, Ottaviani F et al (2017) Modern management of paediatric obstructive salivary disorders: long-term clinical experience. La gestione moderna dei disordini ostruttivi salivari in età pediatrica: esperienza clinica a lungo termine. Acta Otorhinolaryngol Ital 37(2):160-167. https://doi.org/10.14639/0392-100X-1607

\section{Publisher's Note}

Springer Nature remains neutral with regard to jurisdictional claims in published maps and institutional affiliations.

\section{Submit your manuscript to a SpringerOpen ${ }^{\circ}$ journal and benefit from:}

- Convenient online submission

- Rigorous peer review

- Open access: articles freely available online

- High visibility within the field

- Retaining the copyright to your article

Submit your next manuscript at $\boldsymbol{\nabla}$ springeropen.com 